\title{
On Why Left Events are the Right Ones: Neural Mechanisms Underlying the Left-hemifield Advantage in Rapid Serial Visual Presentation
}

\author{
Rolf Verleger ${ }^{1}$, Andreas Sprenger ${ }^{1}$, Sina Gebauer ${ }^{1}$, \\ Michaela Fritzmannova $^{1}$, Monique Friedrich ${ }^{1}$, Stefanie Kraft $^{1,2}$, \\ and Piotr Jaśkowski ${ }^{1,3}$
}

\begin{abstract}
When simultaneous series of stimuli are rapidly presented left and right, containing two target stimuli T1 and T2, T2 is much better identified when presented in the left than in the right hemifield. Here, this effect was replicated, even when shifts of gaze were controlled, and was only partially compensated when T1 side provided the cue where to expect T2. Electrophysiological measurement revealed earlier latencies of $\mathrm{T} 1$ - and $\mathrm{T} 2$-evoked $\mathrm{N} 2 \mathrm{pc}_{\mathrm{p}}$ peaks at the right than at the left visual cortex, and larger right-hemisphere T2-evoked $\mathrm{N} 2{ }_{\mathrm{pc}}$ amplitudes when T2 closely followed T1. These findings suggest that the right hemisphere was better able to sin-
\end{abstract}

\section{INTRODUCTION}

The right hemisphere of the human brain probably is dominant for some relevant processes that constitute human perception. This assumption may be suggested from dysfunctions that occur after lesions to the right hemisphere. Notably, in the syndrome of hemineglect, lesions to the right temporo-parietal junction lead to loss of awareness for contralesional aspects of the patients' world (Danckert \& Ferber, 2006; Driver \& Vuilleumier, 2001). Right-hemisphere dominance may also be inferred from increased activation of right-hemisphere areas when healthy persons are required to shift and focus their attention (Nobre et al., 1997; Corbetta, Miezin, Shulman, \& Petersen, 1993; although see Woldorff et al., 2004) and from increased sensitivity of perception to being perturbed by transcranial magnetic stimulation when pulses are applied to right-hemisphere areas (Chambers, Payne, Stokes, \& Mattingley, 2004; Rushworth, Ellison, \& Walsh, 2001). However, there is only weak asymmetry of perceptual skills in everyday life in favor of stimuli presented in the left hemifield, thus perceived by the right hemi-

\footnotetext{
${ }^{1}$ University Lübeck, Lübeck, Germany, ${ }^{2}$ University Clinic Eppendorf, Hamburg, Germany, ${ }^{3}$ University of Finance and Management, Warsaw, Poland
}

gle out the targets in time. Further, sustained contralateral slow shifts remained active after T1 for longer time at the right than at the left visual cortex, and developed more consistently at the right visual cortex when expecting T2 on the contralateral side. These findings might reflect better capacity of right-hemisphere visual working memory. These findings about the neurophysiological underpinnings of the large right-hemisphere advantage in this complex visual task might help elucidating the mechanisms responsible for the severe disturbance of hemineglect following damage to the right hemisphere.

sphere (see, e.g., Corballis, 1997 for a review on mental rotation). This differs from left-hemisphere dominance for hand control, which is immediately evident in everyday life by the greater skill of the contralateral right hand in exerting all kinds of activities. Such asymmetry would provide an important piece of converging evidence for right-hemisphere dominance of perceptual control. Lacking this immediately plausible evidence in healthy persons, it may even be argued that left hemineglect after right-hemisphere lesions reveals left- rather than right-hemisphere dominance in attentional control (Kinsbourne, 1987). Therefore, it would be of great interest to have a perceptual task where there is considerably better performance with left-field stimuli, and to study the brain mechanisms related to that better performance.

Such a task was recently discovered by Holländer, Corballis, and Hamm (2005) by using rapid serial visual presentation (RSVP) of two streams of letters that ran simultaneously at two locations, left and right from fixation. Two target stimuli had to be identified, "T1" and "T2" (first and second targets). Research on rapid series presented at one location has well established that probabilities of identifying $\mathrm{T} 2$ principally depend on the lag between $\mathrm{T} 1$ and $\mathrm{T} 2$, being very high when T2 directly follows T1 ("lag 1-sparing"), relatively low with a lag of 200-300 msec (the "attentional blink"; Raymond, 
Shapiro, \& Arnell, 1992), and recovering with longer lags. This time course is probably due to T1 temporarily increasing the level of attention, which makes the following distracters processed attentively (Olivers, 2007), thereby impeding participants' shifting to the new criteria needed for detecting T2 (Nieuwenstein \& Potter, 2006; Di Lollo, Kawahara, Ghorashi, \& Enns, 2005). Several previous studies had used simultaneous RSVP at different locations in order to explore how far these regularities generalize to multiposition displays (Vachon, Tremblay, \& Jones, 2007; Dell'Acqua, Pascali, Jolicour, \& Sessa, 2003; Peterson \& Juola, 2000; Shih, 2000; Breitmeyer, Ehrenstein, Pritchard, Hiscock, \& Crisan, 1999). Unlike those studies, Holländer, Corballis, and Hamm (2005) scored performance separately for right and left sides. They found $20 \%$ to $30 \%$ better identification of T2 when $\mathrm{T} 2$ occurred on the left, particularly when T2 was presented briefly after $\mathrm{T} 1$ in a different stream. These differences between sides were replicated by Scalf, Banich, Kramer, Narechania, and Simon (2007, Experiment 6) and Holländer, Hausmann, Hamm, and Corballis (2005).

In the present study, we set out to extend those findings. With respect to behavioral results, we expected to replicate the marked differences between hemifields (Experiment 1). Additionally, we investigated whether this asymmetry would be reduced when participants know that T2 is presented on the side opposite to T1 only (Experiment 2; cf. Vachon et al., 2007; Potter, 2006) and when eye movements are controlled (Experiment 3).

Of major interest were neurophysiological differences between right and left visual cortices in the way they process the targets presented in their associated contralateral hemifield. A convenient way of measuring brain activity in rapid processing of lateral targets is by recording voltage differences between the visual cortices contralateral minus ipsilateral to targets. By using this approach, nonlateralized activity will be subtracted out. In the present dual-stream RSVP task, this feature is particularly useful because it means getting rid of the bulk of potentials evoked by the distracter stimuli which, being presented in parallel in both hemifields, are not expected to evoke lateralized potentials, whereas the targets, as lateral relevant stimuli, are expected to evoke the " $\mathrm{N} 2$ pc " component (negative peak in the time range of the "N2" peak, "posterior contralateral"). $\mathrm{N} 2 \mathrm{pc}_{\mathrm{pc}}$ has been obtained in previous studies on single left-right pairs of relevant and irrelevant stimuli as a distinct peak in the contralateral-ipsilateral difference waveshape at about 250 msec after target onset (Wauschkuhn et al., 1998; Eimer, 1996), sometimes followed by a second peak or by a tonic surplus of contralateral negativity (Vogel \& Machizawa, 2004; Wauschkuhn et al., 1998). Indeed, some recent studies measured contralateralipsilateral differences in variants of RSVP tasks, presenting either T2 or both T1 and T2 laterally, and obtained both the phasic $\mathrm{N} 2 \mathrm{pc}$ and the tonic component in response to these lateralized stimuli (Dell'Acqua, Sessa,
Jolicœur, \& Robitaille, 2006; Jolicœur, Sessa, Dell'Acqua, \& Robitaille, 2006). $\mathrm{N} 2{ }_{\mathrm{pc}}$ has been interpreted as a correlate of selectively processing the target features, reflecting either this very process (Verleger \& Jaśkowski, 2007; Eimer, 1996) or the suppression of distracting information (Hopf et al., 2006; Luck \& Hillyard, 1994). The following tonic component has been shown to faithfully reflect load and individual capacities of visual working memory (Vogel, McCollough, \& Machizawa, 2005; Vogel \& Machizawa, 2004) but has also been obtained without any obvious relation to working memory, for example, when the two searched-for target colors were in the same hemifield (Woodman \& Luck, 1999), probably just reflecting ongoing relevant stimulation from the same hemifield.

These contralateral-ipsilateral differences were here separately formed for left and right targets. If better identification of left-sided T2 would, indeed, reflect superior abilities of the perceiving right hemisphere, then $\mathrm{N} 2{ }_{\mathrm{pc}}$ and the tonic component should differ between left and right targets. To detail, the right hemisphere might be faster than the left in processing its contralateral stimuli. Such speed differences could be reflected in earlier peak latencies of $\mathrm{N} 2{ }_{\mathrm{pc}}$ for left stimuli, both T1 and T2. Additionally, or alternatively, the right hemisphere might get more activated by its contralateral stimuli. Such sensitivity differences could be reflected by larger amplitudes with left stimuli, both of $\mathrm{N} 2{ }_{\mathrm{pc}}$ and of the following tonic component. Additionally, in Experiment 2 where participants were prompted by $\mathrm{T} 1$ to expect $\mathrm{T} 2$ on a predetermined side, the right hemisphere might be better able than the left to prepare processing of T2 expected in its contralateral hemifield. Such differences in preparatory activity might be reflected by larger amplitudes of the tonic component in the interval between T1 and T2.

\section{METHODS}

\section{Participants}

Students of the University of Lübeck participated for $€ 7$ per hour: 14 at Experiment 1, 12 each at Experiments 2a and 2b, and 16 at Experiment 3. All participants had normal or corrected-to-normal vision and normal color vision. Informed written consent was obtained. Because of systematic eye movements toward the targets, affecting the EEG, 4 of 14 had to be excluded from Experiment 1 , and 2 of 12 from Experiment $2 \mathrm{a}$. Of interest, these excluded participants also had lowest identification performance. Three of the 16 participants of Experiment 3 prematurely terminated the session, unable to endure the load of the eye-tracking device firmly strapped to their head. The remaining participants were: 10 in Experiment 1 ( 7 men, 3 women; ages ranging between 24 and 28 years; mean $=25$ years), 10 in Experiment $2 \mathrm{a}$ ( 3 men, 7 women; $22-30$ years, mean $=25$ years $)$, 
12 in Experiment 2b (3 men, 9 women; 22-32 years, mean $=26$ years), 13 in Experiment 3 ( 6 men, 7 women; 22-38 years, mean $=27$ years). One participant in Experiment 1 was left-handed, as examined by the Edinburgh Handedness Inventory (score of -0.3 ), but remained in the sample because his performance did not conspicuously differ from the other participants.

\section{Stimuli}

Two simultaneous sequences of black letters were rapidly presented at a rate of 9.4 frames/second, left and right from fixation (Figure 1). The one red letter (first target $=$ "T1") and the one black digit (second target $=$ "T2") had to be identified amidst the black letters. T1 was left or right, and T2 followed T1 with some lag either on the same side as $\mathrm{T} 1$ or on the other side. Stimuli were the capital letters of the alphabet and the digits 1 to 6 . Target sets consisted of the six stimuli D, F, G, J, K, L for T1, and 1, 2, 3, 4, 5, 6 for T2. This set size of 6 was chosen to be large enough to decrease the chance of making a correct guess and to be small enough to make the task of entering the response on the keyboard not too complex. The distracter set consisted of all other letters. Stimuli were $8.5 \mathrm{~mm}$ wide and $11 \mathrm{~mm}$ high $\left(0.5^{\circ} \times 0.6^{\circ}\right)$ and were presented on the white background of a 17-in. screen driven with $75 \mathrm{~Hz}$ at about $1.2 \mathrm{~m}$ from participants' eyes. The two simultaneous streams were presented left and right from fixation, with the inner edge of the stimuli $10 \mathrm{~mm}$ from fixation $\left(0.6^{\circ}\right)$. Fixation was marked by a small red cross, $0.1^{\circ} \times 0.1^{\circ}$. Each left-right pair of stimuli was presented for $107 \mathrm{msec}$, immediately followed by the next pair.

In any trial, distracter stimuli were randomly selected with replacement from the distracter set, and $\mathrm{T} 1$ and T2 were randomly selected from the two target sets. Both T1 and T2 were accompanied by a distracter let-

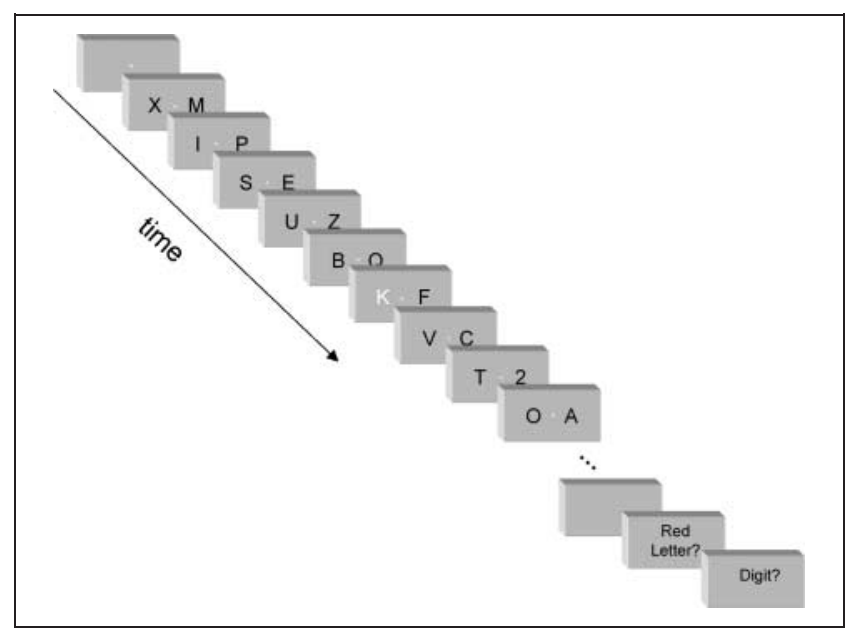

Figure 1. Sequence of events in a trial (see Methods for details). Red color is replaced here by white color. ter on the other side. Five, 7, or 9 distracter pairs preceded T1 to make precise temporal expectancies difficult (Naccache, Blandin, \& Dehaene, 2002). T1 was presented with equal probability either in the left or in the right stream. In Experiments 1 and 3, T2 occurred with equal probability either in the same stream as T1 or in the other stream. In Experiment 2, side of T2 was determined by side of T1, T2 being presented in Experiment $2 \mathrm{a}$ on the other side and in Experiment $2 \mathrm{~b}$ on the same side as T1. In Experiments 1 and 3, T1 was followed by T2 either immediately, with 107 msec stimulus onset asynchrony (SOA), termed Lag 1, or with one or four pairs of intervening distracters (214 and $535 \mathrm{msec}$ SOA), termed Lag 2 and Lag 5. There was more room for lag variations in Experiment 2 because T2 side was fixed, so T2 was presented, equally probably (17\% each), at Lags 1, 2, 3, 4, 5, or not at all. T2 was followed by five pairs of distracters to have equal distance between T2 and the end of trial for each T1-T2 lag. Therefore, trial length varied between 12 pairs (when T1 came at 6th position and T1-T2 lag was 1) and 20 pairs (when T1 came at 10th position and T1-T2 lag was 5).

\section{Procedure}

Participants were seated in a comfortable armchair in a darkened chamber in front of the computer screen. Presentation software, version 0.76, was used for experimental control (Neurobehavioral Systems). Each trial started with the fixation cross, and the letter streams had their onset $0.8 \mathrm{sec}$ later. The fixation cross was extinguished $2.1 \mathrm{sec}$ after onset of the letter stream. Then, participants had to enter their response on the keyboard that they held on their lap, first the T1 letter on the middle row of the keyboard, then the $\mathrm{T} 2$ digit on the number pad. Some response had to be entered in any case, even when participants did not know the answer or when, untold to subjects, no T2 at all was presented (in $17 \%$ of trials of Experiment 2). The next trial started after the responses for $\mathrm{T} 2$ were given. Pooling across variation of $\mathrm{T} 1$ timing, there were 12 conditions in each experiment, left/right T1 $\times$ left/right T2 $\times 3$ lags in Experiments 1 and 3, and left/right T1 $\times 6$ lags in Experiment 2 . These 12 conditions were each replicated 60 times, in random sequence, with a break after 360 trials. Before the task proper, some trials were presented in slow motion, with 507 msec rather than 107 msec SOA, to familiarize participants with the task.

\section{EEG Recording and Processing}

EEG was recorded with Ag/AgCl electrodes (FMS, Munich) from 19 scalp sites (F3, Fz, F4, FC3, FC4, C3, C1, Cz, C2, C4, P7, P3, Pz, P4, P8, PO7, PO8, O1, O2) and from the nose-tip. The ground electrode was placed at $\mathrm{FCz}$, online reference was Fz. For artifact control, vertical EOG was recorded from above versus below the right eye, 
horizontal EOG (hEOG) from positions next to the outer rims of the eyes. Data were amplified from DC to $1000 \mathrm{~Hz}$ by a BrainAmp MR plus and stored at $250 \mathrm{~Hz}$ per channel. Using Brain-Vision Analyzer software, data were off-line re-referenced to the nose-tip, low-pass filtered at $20 \mathrm{~Hz}$, segmented from $100 \mathrm{msec}$ before T1 until $1500 \mathrm{msec}$ afterward, referred to the first $100 \mathrm{msec}$ as baseline, and edited for artifacts, by rejecting trials with zero lines, by correcting ocular artifacts using the linear regression method implemented in the Analyzer software, and by rejecting trials with voltage differences $\geq 200 \mu \mathrm{V}$ or voltage steps $\geq 50 \mu \mathrm{V}$. Data were averaged across artifact-free trials with correct behavioral performance (disregarding the T2 response in the 17\% no-T2 trials of Experiment 2), separately for each condition and participant. To obtain contralateral-ipsilateral differences of each symmetric left-right pair of recording sites, the left-site average was subtracted from the right-site average when T1 was left (e.g., PO8-PO7), vice versa when T1 was right (e.g., PO7-PO8). Grand means over participants were calculated for illustrating the results. Contralateral-ipsilateral differences were also formed for hEOG. Any participant's data were rejected if these hEOG difference waveshapes showed systematic deviations from baseline within $500 \mathrm{msec}$ after T1 onset, indicating eye movements toward the targets. As mentioned above in the Participants section, this criterion led to exclusion of 6 of the 38 participants at Experiments 1 and 2 .

\section{Infrared Recording of Eye Movements}

In Experiment 3, movements of the left and right pupils were recorded by infrared cameras (EyeLinkII System, SR Research, Osgood/CA), mounted below either eye by being fixed to a belt tightened around the head. Additionally, EEG and EOG were recorded, as in the other experiments. Horizontal and vertical positions of the pupils were tracked with reference to subjective straightahead, were transformed to digital values at $500 \mathrm{~Hz}$ and stored on computer, together with time markers of stimulation, using the EyeLink software, version 2.21. Spatial resolution of eye position was $\leq 0.25^{\circ}$. Off-line, by means of an interactive program written in Matlab 7.0, single-trial traces of horizontal and vertical positions were visually inspected for deviation from horizontal midline. Trials were classified to be free from gaze shifts if horizontal position deviated from midline by less than $1^{\circ}$ within the 2 -sec train of stimulation and if no saccades larger than $1^{\circ}$ were noted within this time interval. After being added to the marker files of the EEG recording, these trial classifications could be used for analysis of behavioral performance and of EEG. Gaze shifts were additionally classified for timing and direction, before and after T1 and T2, and away from or toward the target. But, occurring too infrequently, these details on timing and direction will not be reported.

\section{Data Analysis}

For analysis of overt behavior, percentages of trials with correct responses were computed in each condition: T1-correct relative to all trials, and both T1- and T2correct relative to all correct $\mathrm{T} 1$ trials.

EEG data analysis focused on the contralateralipsilateral differences at PO7-PO8, after having inspected topographical maps of voltage distribution and the waveforms at the other pairs of left-right symmetric recording sites. In Experiment 1 , the peak of $\mathrm{N} 2 \mathrm{pc}$ evoked by $\mathrm{T} 1$ was measured as most negative peak 170 260 msec after T1 onset. To control for possible earlier effects overlapping $\mathrm{N} 2_{\mathrm{pc}}$, the preceding $\mathrm{P} 1_{\mathrm{pc}}$ was measured as mean amplitude 120-140 msec after T1 onset. To assess slow shifts of the contralateral-ipsilateral differences following the phasic $\mathrm{N} 2{ }_{\mathrm{pc}}$, mean amplitudes of adjacent epochs of $50 \mathrm{msec}$ were formed, from $300 \mathrm{msec}$ after T1 onset onward. To be unaffected by T2-evoked potentials, these epochs only were measured in the Lag 5 data of Experiment 1, until $700 \mathrm{msec}$, and in the no-T2 data of Experiment 2, until 900 msec. T2-evoked N2 pc had a clear peak at Lag 5 only and was therefore measured as mean amplitude 200-300 msec after T2 onset (307-406 msec, 414-513 msec, 735-834 msec after T1 with Lags 1, 2, 5) and additionally, to measure peak latency, at Lag 5 as most negative peak within 165300 msec after T2 onset. To prevent aftereffects of T1 from affecting this measurement, these measurements were made in Lag 1 and Lag 2 averages after subtracting the Lag 5 averages which contained only T1 activity in the relevant time interval, which thus was subtracted out (see Figure 6) and in Lag 5 averages by using the epoch as baseline where T1 was most remote and yet T2 effects had not yet started (600-650 msec; cf. Figure 6).

Effects were tested by univariate analysis of variance (ANOVA). The basic ANOVA design had the repeated measurement factors target side (left, right; with "target" being T1 or T2, depending on the analysis), side of the other target (same, different; in Experiment 2, this was a between-subjects factor), and lag (1, 2, 5; in Experiment 2: 1, 2, 3, 4, 5). In ERP analyses of topographical distributions, an eight-level factor of topography was additionally defined (|F3-F4|, |FC3-FC4|, |C1-C2|, |C3-C4|, |P3-P4|, |P7-P8|, |PO7-PO8|, |O1-O2|). When repeated measurement factors had more than two levels (lag and topography), degrees of freedom were downmultiplied by the Greenhouse-Geisser coefficient. Probabilities according to these corrected degrees of freedom are reported throughout.

\section{RESULTS}

\section{Identification Performance}

Percentages of trials in which the targets were identified are compiled in Table 1. 
Table 1. Percentages of Correct Identification of Targets

\begin{tabular}{|c|c|c|c|c|c|c|c|c|c|c|c|c|}
\hline \multirow{3}{*}{$\frac{\text { Lag: }}{\frac{\text { T1-T2 Sides: }}{\text { Target Side: }}}$} & \multicolumn{4}{|c|}{1} & \multicolumn{4}{|c|}{2} & \multicolumn{4}{|c|}{5} \\
\hline & \multicolumn{2}{|c|}{ Same } & \multicolumn{2}{|c|}{ Different } & \multicolumn{2}{|c|}{ Same } & \multicolumn{2}{|c|}{ Different } & \multicolumn{2}{|c|}{ Same } & \multicolumn{2}{|c|}{ Different } \\
\hline & Left & Right & Left & Right & Left & Right & Left & Right & Left & Right & Left & Right \\
\hline \multicolumn{13}{|l|}{$T 2 \mid T 1$} \\
\hline Experiment 1 & $98(3)$ & $98(3)$ & 78 (13) & $48(9)$ & $86(13)$ & $84(14)$ & $76(18)$ & $48(9)$ & $81(13)$ & $73(13)$ & 89 (10) & $76(10)$ \\
\hline Experiment 2 & $96(6)$ & $97(6)$ & $76(20)$ & 57 (19) & $90(9)$ & 89 (10) & $82(11)$ & 65 (19) & $83(11)$ & $80(15)$ & $90(8)$ & 87 (9) \\
\hline Experiment 3 & $93(14)$ & $94(8)$ & $64(21)$ & $46(23)$ & $76(20)$ & $75(25)$ & $56(26)$ & $45(21)$ & 65 (19) & $52(22)$ & $59(24)$ & $50(27)$ \\
\hline \multicolumn{13}{|l|}{$T 1$} \\
\hline Experiment 1 & $72(12)$ & $85(8)$ & 75 (11) & $75(11)$ & 77 (8) & $81(9)$ & 77 (8) & $78(9)$ & $79(8)$ & $81(7)$ & $78(10)$ & 79 (10) \\
\hline Experiment 2 & $81(9)$ & $80(10)$ & $73(14)$ & $72(11)$ & $80(11)$ & $79(14)$ & $75(14)$ & $73(11)$ & $81(12)$ & $81(14)$ & $72(16)$ & $73(12)$ \\
\hline Experiment 3 & 70 (19) & $68(17)$ & $69(17)$ & $65(20)$ & $66(22)$ & $66(20)$ & $70(20)$ & 66 (19) & $66(24)$ & $64(23)$ & $70(20)$ & $66(20)$ \\
\hline
\end{tabular}

Upper half: Identification of T2, relative to those trials where T1 was identified.

Lower half: Identification of T1, relative to all trials.

Thus, "Target Side" (entries in third row) refers to T2 side in the upper half, and to T1 side in the lower half.

Values are presented as means across participants $(S D)$.

For Experiment 2, entries for same side are from Experiment 2b, for different side from Experiment $2 \mathrm{a}$.

\section{Experiment 1: Identification of T2}

In addition to Table 1 , mean rates of $\mathrm{T} 2$ identification are depicted in the upper panel of Figure 2. All main effects were significant $[$ Lag: $F(2,18)=8.0, p=.004$; T2 side: $F(1,9)=21.1, p=.001 ; \mathrm{T} 1$ side (same vs. different): $F(1$, $9)=100.3, p<.001]$. These effects were further qualified by the following interactions. When $\mathrm{T} 1$ and $\mathrm{T} 2$ were on the same side, identification was almost perfect with Lag 1 and then decreased across lags [Lag $\times$ T1 side: $F(2,18)=42.9, p<.001$; separate effect of lag for sameside T1: $F(2,18)=20.0$ ]. In contrast, when sides of T1 and $\mathrm{T} 2$ differed, identification was at a low level for Lags 1 and 2, and then increased [separate effect of lag for different-side T1: $F(2,18)=41.2]$. Of particular interest, T2 side had a strong effect with different-side T1, especially at the two shorter SOAs, where left T2 was identified in $77 \%$ of trials and right-side T2 in $48 \%$ only [T2 side $\times$ T1 side: $F(1,9)=94.2, p<.001$; separate effect of T2 side for same-side T1: $F(1,9)=1.9$, for different-side T1: $F(1,9)=41.2]$. This effect decreased across lags [T2 side $\times$ T1 side $\times$ Lag: $F(2,18)=7.8$, $p=.005$ ] but was still reliable for different-side T1 even with Lag 5 [89\% vs. $76 \% ; F(1,9)=23.3]$.

\section{Experiment 1: Identification of T1}

T1 was identified in $78 \%$ of the trials. Right T1 was identified better when also T2 was right than when T2 was left $(82 \%$ vs. $78 \%)$ [T1 side $\times$ T2 side: $F(1,9)=5.7, p=$ .04 ; separate effect of $\mathrm{T} 2$ side for right $\mathrm{T} 1: F(1,9)=7.5$, $p=.02$; for left T1: $F(1,9)=0.2$, ns $(76 \%$ and $77 \%)]$.
Note that the interaction of T1 side $\times$ T2 side could not be resolved to effects of T1 side [effect of T1 side when T2 was on the same side: $F(1,9)=2.8, p=.13$; for different-side T2: $F(1,9)=0.0, n s]$. The effect tended to be present for Lag 1 only [T1 side $\times$ Lag: $F(2,18)=3.7$, $p=.050 ; \mathrm{T} 1$ side $\times \mathrm{T} 2$ side $\times$ Lag: $F(2,18)=3.5, p=$ .058 ; $\mathrm{T} 1$ side $\times \mathrm{T} 2$ side for Lag 1 separately: $F(1,9)=$ 9.7, $p=.01$; for Lags 2 and 5 separately: $F(1,9)<1.9$, $p>.21]$ (lower half of Table 1).

Because of this effect on T1 identification, percentages of T2 identification were reanalyzed to include also trials in which T1 had not been identified. However, these effects did not appreciably change.

\section{Experiment 2: Compensation by Expectancy}

Mean rates of T2 identification in Experiment 2 are depicted in the lower panel of Figure 2. In Experiment 2a, sides of T1 and T2 were always different. Even with this possibility that, upon perceiving $\mathrm{T} 1$, participants knew where to expect $\mathrm{T} 2$, right $\mathrm{T} 2$ was identified worse than left T2, except for the longest lag [T2 side: $F(1,9)=11.4$, $p=.008$; Lag $\times$ T2 side: $F(4,36)=4.9, p=.01 ; t$ tests for each lag from 1 to 5 yielded $p=.04$ or better for Lags 1 , $2,3,4]$. Comparison to the different-side results from Experiment 1 in an ANOVA on the common Lags 1,2, and 5 showed that expectancy improved identification of right T2 from 57\% in Experiment 1 to $70 \%$ in Experiment 2a (averaged across lags) and did not further improve identification of left T2 [81\% vs. 83\%; Experiment $\times$ T2 side: $F(1,18)=3.7, p=.07$; effect of experiment separately for 


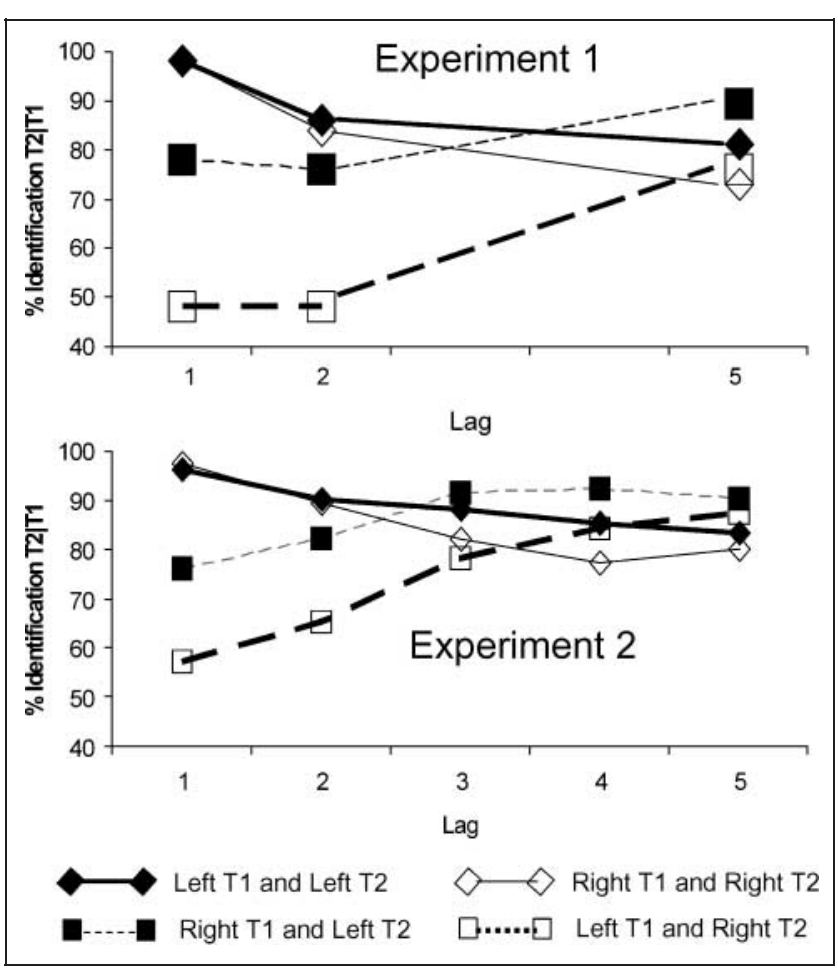

Figure 2. Identification rates for T2 in Experiments 1 and 2. Displayed are percentages of correct T1 and T2 trials relative to all trials in which T1 was identified. Top: Experiment 1; Bottom: Experiment 2, in which side of $\mathrm{T} 2$ was predictable from presentation side of T1, either always differing from T2 (dashed lines) or always the same as T1 (solid lines). Bold lines and filled symbols are for left side, thin lines and empty symbols for right side. Diamonds and solid lines denote trials where sides of T1 and T2 were the same, squares and dashed lines denote trials where sides of T1 and T2 differed. Therefore, bold solid lines with filled diamonds: T1 left, T2 left; thin solid lines with empty diamonds: T1 right, T2 right; thin dashed lines with filled squares: T1 right, T2 left; bold dashed lines with empty squares: T1 left, T2 right.

right T2: $F(1,18)=7.0, p=.02$; for left T2: $F(1,18)=$ $0.1, n s]$. Identification rate of $\mathrm{T} 1$ was $72 \%$ and was not affected by T1 side or lag (all $F<1.9, p>.16$ ).

In Experiment 2b, T2 always appeared on the same side as T1. Even here, left T2 was better identified than right T2 for the Lags 3 and 4, not used in Experiment 1 $[$ Lag $\times$ T2 side: $F(4,44)=3.1, p=.047 ; t$ tests were marginally significant for $\operatorname{Lag} 3, p=.06$, and significant for $\operatorname{Lag} 4, p=.04]$. At the lags common to both experiments, expectancy could not further improve the good identification of same-side T2 already achieved in Experiment 1: Comparison to same-side results from Experiment 1 yielded no effect of experiment, all $F$ values being $\leq 1.5$, $p \geq .23$. Identification rate of $\mathrm{T} 1$ was $80 \%$ and was not affected by T1 side or lag (all $F<1.3, p>.30$ ).

\section{Electrophysiology}

\section{Phasic T1-evoked Activity}

Figure 3 displays difference waveshapes contralateralipsilateral to T1, pooled over Lags 1, 2, 5, separately for left T1 and right T1. Conspicuous features are a "P1 $1_{\mathrm{pc}}$ " (contralateral positivity) peaking at $130 \mathrm{msec}$, followed by the expected " $\mathrm{N} 2_{\mathrm{pc}}$."

In the overall ANOVA on the contralateral-ipsilateral differences of all eight pairs of sites, mean amplitudes 120-140 msec after T1 onset were more positive in posterior than anterior differences, consistent with the presence of a posterior $\mathrm{P} 1_{\mathrm{pc}}$ [Sites: $F(7,63)=9.2$, $p=.001]$, and did not differ between left and right T1 [T1 side: $F(1,9)=1.6, n s$; T1 side $\times$ Site: $F(7,63)=2.2$, $p=.14$; effects of $\mathrm{T} 1$ side at single pairs of sites were largest at $|\mathrm{O} 1-\mathrm{O} 2|, F(1,9)=3.2, p=.11$, and at $|\mathrm{P} 7-\mathrm{P} 8|$, $F(1,9)=2.7, p=.14]$

$\mathrm{N} 22_{\mathrm{pc}}$ was largest at $|\mathrm{PO} 7-\mathrm{PO} 8|$, followed by $|\mathrm{P} 7-\mathrm{P} 8|$ [Sites: $F(7,63)=18.54, p<.001$ ], as shown by Figure 3 . T1 side did not have effects on $\mathrm{N} 2_{\mathrm{pc}}$ amplitudes but did so on latencies, with $\mathrm{N} 2_{\mathrm{pc}}$ reaching its peak earlier after left than after right $\mathrm{T} 1[F(1,9)=8.4, p=.02]$, for instance, at |PO7-PO8| $209 \mathrm{msec}$ versus $224 \mathrm{msec}$. There was no difference between sites, therefore the effect of T1 side was significant at $p<.07$ or better at most pairs of sites when tested separately (|F3-F4|, |FC3-FC4|, |C1C2|, |C3-C4|, |P3-P4|, |PO7-PO8|, but neither at hEOG $(p=.92)$ excluding a confounding effect of gaze shifts, nor at the two pairs of sites where $\mathrm{P} 1_{\mathrm{pc}}$ tended to differ between $\mathrm{T} 1$ sides $(|\mathrm{P} 7-\mathrm{P} 8|: p=.30 ;|\mathrm{O} 1-\mathrm{O} 2|: p=.41)$, possibly due to some influence of that $\mathrm{P} 1_{\mathrm{pc}}$ effect extending to the $\mathrm{N} 2_{\mathrm{pc}}$ window.

\section{Aftereffects of T1-evoked Activity}

Inspection of Figure 3 suggests that there was sustained contralateral negativity following $\mathrm{N} 2 \mathrm{pc}$. To exclude any interfering effects of $\mathrm{T} 2$, these aftereffects were measured with the longest lag. The |PO7-PO8| waveforms are displayed in Figure 4 . The phasic $\mathrm{N} 22_{\mathrm{pc}}$ peak returned to zero when T1 was on the right side, but continued as a sustained relative negativity over the right visual cortex when T1 was left, significantly differing between T1 sides at 550-600 msec $[F(1,9)=5.1, p=.05]$ and at 600 $650 \mathrm{msec}[F(1,9)=7.6, p=.02]$. The effect on this sustained negativity was even larger at $|\mathrm{P} 7-\mathrm{P} 8|$ [at 550 600 msec: $F(1,9)=11.2, p=.009$; at $600-650$ msec: $F(1$, 9) $=15.3, p=.004]$.

\section{Modification of T1 Aftereffects by Expectancy}

In Experiment 2, $\mathrm{T} 2$ exclusively appeared either on the side opposite to T1 or on the same side as T1. Figure 5 displays difference waveforms recorded at the posterior sites |PO7-PO8| from that $1 / 6$ of trials in which no T2 at all was presented, reflecting the pure effect of expectancy. Data are displayed with reference to T2 side. If expectancy of $\mathrm{T} 2$ is reflected in negativity contralateral to the expected side, the level of contralateral-ipsilateral difference should be above baseline: Either stay above 
Figure 3. T1-evoked contralateral-ipsilateral differences in Experiment 1. Displayed are grand means of the |left-right| differences, contralateral minus ipsilateral to the side of T1. Upper part: Waveforms recorded from all eight pairs of symmetrical sites and horizontal EOG. The thin waveforms are from trials with right T1 (left minus right site, e.g., $\mathrm{PO} 7-\mathrm{PO} 8$ ), the bold ones from trials with left T1 (right minus left site, e.g., PO8-PO7) Time-point zero is T1 onset. The vertical arrows pointing to the $x$-axis denote the three alternative time points of $\mathrm{T} 2$ onset (across which these data are averaged). Lower part: Topographic distribution of the contralateral-ipsilateral differences at the time point of the $\mathrm{N}_{\mathrm{pc}}$ peak. Depicted are halves of the scalp: Left-right differences with right $\mathrm{T} 1$ are mapped on the left half, and right-left differences with left T1 are mapped on the right half. View is from above, with the nose on top and back of the head on the bottom. These maps were computed using spherical splines of third order with a maximum of 10 Legendre polynomials.

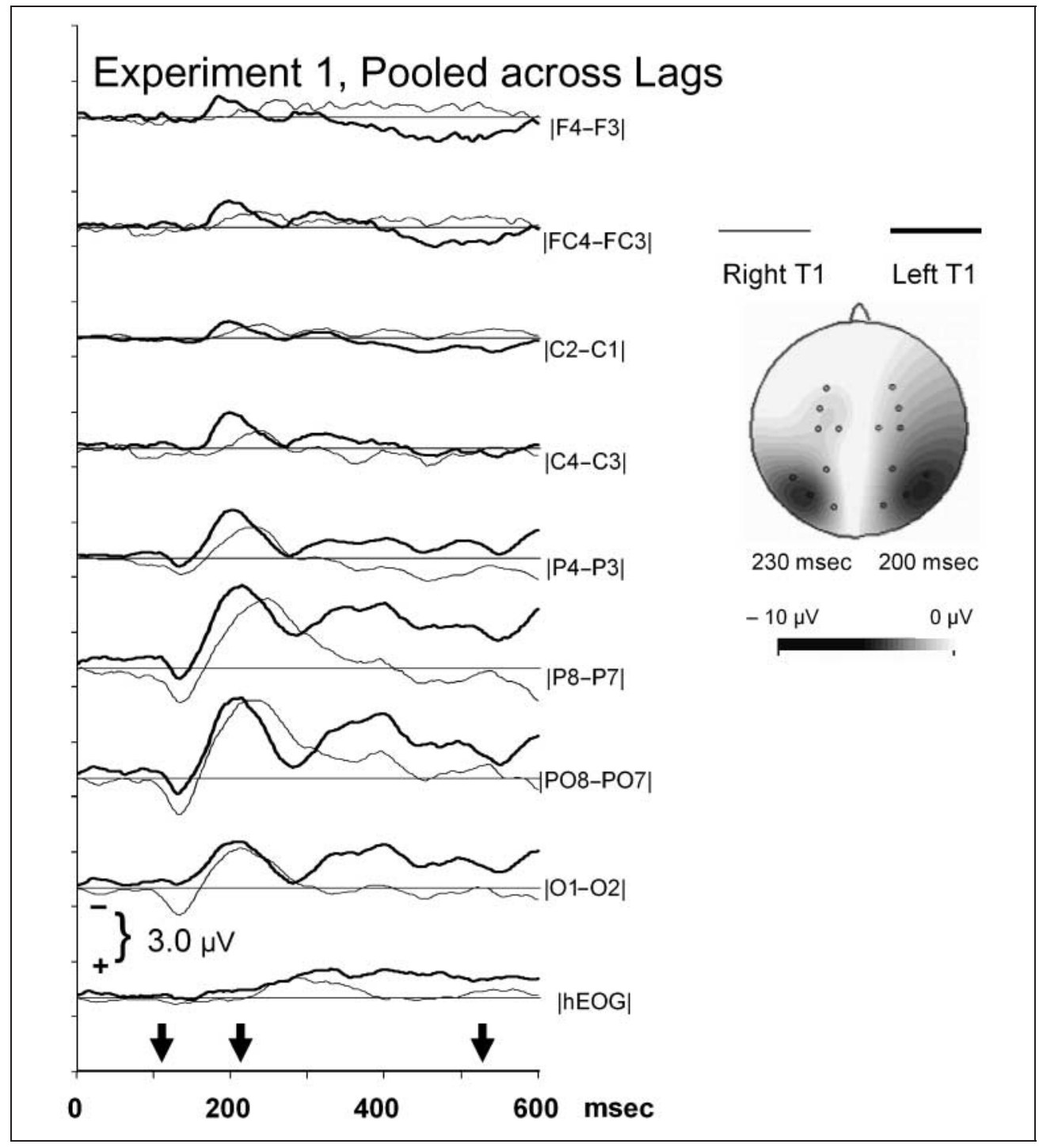

baseline when $\mathrm{T} 2$ is expected on the same side as $\mathrm{T} 1$ (Figure 5, top) or rise above baseline when T2 is expected on the side opposite to T1 (lower panel of Figure 5). As Figure 5 shows, this rising above baseline did not occur when T2 was expected on the right. Indeed, in ANOVAs of 50-msec epochs (starting at $300 \mathrm{msec}$, after offset of the $\mathrm{T} 1$-evoked $\mathrm{N} 2 \mathrm{pc}$ ), the interaction of $\mathrm{T} 1$ side (same or different as expected T2 side, measured between subjects) $\times$ T2 side (expected left vs. right) was significant at 401-700 msec (except 501-550 msec) $[F(1$, $20) \geq 4.4$ and $\leq 13.6, p \leq .049$ and $\geq .001]$. Posttests exploring these interactions showed that in all analyzed epochs it was expectancy of right T2 after left T1 that differed from the other three conditions by being less negative.

\section{T2-evoked activity}

T2-evoked contralateral-ipsilateral differences are displayed in Figure 6A. Differences are visible between same-side and other-side T2, with more negativity contralateral to T2 at 200-300 msec after T2 onset, consistent with interpretation of these effects as T2-evoked $\mathrm{N} 2$ pc . These T2-evoked potentials evidently rode on the long-lasting T1-evoked activity reported above. Therefore, T1 activity was removed from Lag 1 and Lag 2 waveforms by subtracting the Lag 5 waveforms, leaving T2 activity only. For Lag 5, a baseline close to onset of the T2 effect was chosen, to minimize the impact of T1 aftereffects (Figure 6B). To enable direct comparison of $\mathrm{N} 2{ }_{\mathrm{pc}}$ between same-side and other-side $\mathrm{T} 2$, polarity of other-side $\mathrm{T} 2$ values was inverted before statistical analysis. $\mathrm{N} 22_{\mathrm{pc}}$ amplitudes became larger with longer lags $[F(2,18)=4.9, p=.04]$ and were largest when left T2 was preceded by right $\mathrm{T} 1$ [T2 side $\times \mathrm{T} 1$ side: $F(1,9)=$ $12.0, p=.007$ ]; only left $\mathrm{T} 2$ preceded by right $\mathrm{T} 1$ differed from the other combinations of $\mathrm{T} 1$ and $\mathrm{T} 2$ in posttests. Of interest (see the Discussion), when tested at the three lags separately, this interaction occurred at Lag $1[F(1,9)=8.3, p=.02]$ and at $\operatorname{Lag} 2[F(1,9)=6.6$, 


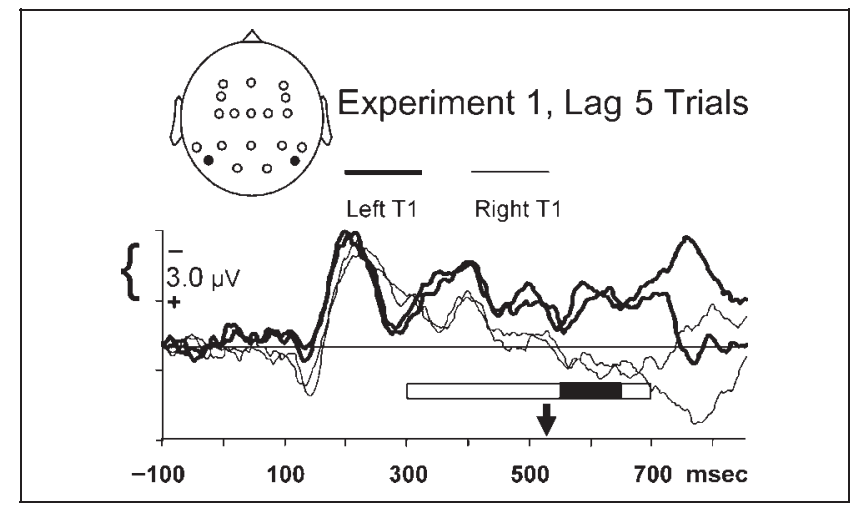

Figure 4. T1-evoked contralateral-ipsilateral differences in Experiment 1 from |PO7-PO8|. Different from Figure 3, only trials with Lag 5 have been included, that is, T2, which is presented at $535 \mathrm{msec}$ (denoted by the vertical arrow pointing to the $x$-axis), does not have relevant impact before $650 \mathrm{msec}$, as is evident from the differences within either pair of bold and thin lines. Time-point zero is T1 onset. The bar below the waveforms displays the results of $F$ tests of effects of T1 site on amplitudes of consecutive 50-msec epochs, starting at 300 msec after T1 onset when the $\mathrm{N} 22_{\mathrm{pc}}$ evoked by $\mathrm{T} 1$ has leveled off. Black filling denotes $p<.05$.

$p=.03]$, but not at $\operatorname{Lag} 5[F(1,9)=0.1, n s]$. However, the triple interaction of T2 side $\times$ T1 side $\times$ Lag was not significant in the main analysis $[F(2,18)=2.3, p=.15]$, leaving this differentiation between lags uncertain.

Close inspection of Figure 6 suggests that peaks of T2-evoked $\mathrm{N} 2_{\mathrm{pc}}$ had later latencies with right than with left T2, at least with Lag 5 (peaks could not be reliably identified at the shorter lags). Indeed, this difference was significant $[F(1,9)=6.7, p=.03 ; 222$ msec vs. $243 \mathrm{msec}$ after T2 onset; $S E M=8 \mathrm{msec}$ in both cases].

\section{Replication with Infrared Eye Tracking}

No saccades or gaze shifts were made in $79 \%$ of trials (range across participants 60-92\%).

\section{Performance in Trials Free from Gaze Shifts}

When only these unaffected trials were analyzed, performance results (Figure 7) were principally similar to Experiment 1 although not equal. Again, T2 identification was affected by all main effects $[\operatorname{Lag}: F(2,24)=12.2$, $p<.001$; T2 side: $F(1,12)=13.7, p=.003$; T1 side (same vs. different): $F(1,12)=36.8, p<.001]$. These effects were qualified by interactions of Lag $\times$ T1 side, T2 side $\times$ T1 side, and by a tendency for Lag $\times$ T2 side. As indicated by the interaction of Lag $\times \mathrm{T} 1$ side $[F(2$, $24)=44.9, p<.001]$, when $\mathrm{T} 1$ and $\mathrm{T} 2$ were on the same side, identification was very good with Lag 1 and then decreased across lags [simple effect of lag for same-side targets: $F(2,24)=33.4, p<.001]$, whereas when sides of $\mathrm{T} 1$ and $\mathrm{T} 2$ differed, identification was low throughout [simple effect of lag for different-side targets: $F(2,24)=$
3.6, ns]. Thus, T2 identification was better with sameside than with different-side T1 with Lags 1 and 2, but not with Lag 5 [effects of T1 side separately for Lags 1, 2, 5 were $F(1,12)=66.5, p<.001 ; F(1,12)=23.5$, $p<.001 ; F(1,12)=0.3, n s]$. Of particular interest, as indicated by the interaction of $\mathrm{T} 2$ side $\times \mathrm{T} 1$ side $[F(1$, $12)=10.2, p=.008]$, T2 side had a moderate effect with same-side T1 [78\% vs. 74\% for left vs. right T2; simple effect of T2 side: $F(1,12)=5.0, p=.045]$ and a strong effect with different-side T1 [63\% vs. 47\% for left vs. right T2; simple effect of T2 side: $F(1,12)=14.2, p=.003$ ]. Further, the left-right difference tended to be particularly marked at Lag 1 and Lag 5 [Lag $\times$ T2 side: $F(2$, $24)=3.3, p=.08$; effects of T2 side at Lag $1: F(1,12)=$ 9.5, $p=.009 ;$ at $\operatorname{Lag} 2: F(1,12)=4.3, p=.06$; at $\operatorname{Lag} 5:$ $F(1,12)=11.4, p=.003]$. Below, these results will be directly compared to the results of Experiment 1.

Identification rate of T1 was $67 \%$ and was not significantly affected by the experimental factors, but the tendency for an interaction of $\mathrm{T} 1$ side $\times \mathrm{T} 2$ side $[F(1$, $12)=3.3, p=.09$ ] replicated the effect from Experiment 1 , such that in a common analysis of both experiments this effect proved highly reliable $[F(1,21)=9.5$, $p=.006]$.

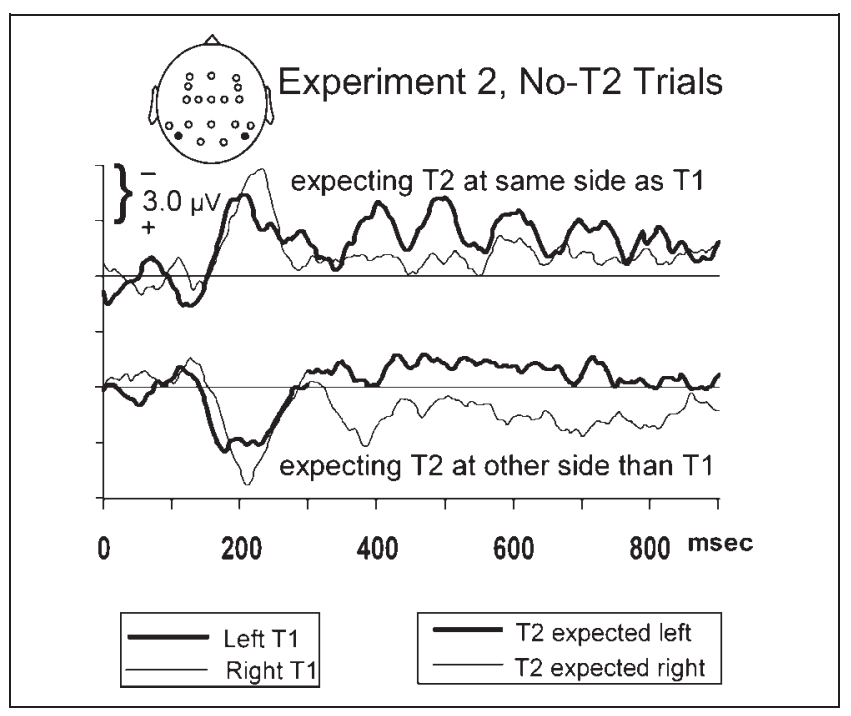

Figure 5. Modification of $\mathrm{T} 1$ aftereffects by explicit expectancies in Experiment 2. Displayed are grand means of the |left-right| differences, contralateral minus ipsilateral to the expected side of T2. These data are from those trials in which no T2 was presented at all $(1 / 6$ of all trials). Time-point zero is T1 onset. T2 was either expected on the same side (top) or on the opposite side (bottom). Polarity was defined such that negativity contralateral to expected $\mathrm{T} 2$ side should be above baseline. Therefore, the $\mathrm{N} 2{ }_{\mathrm{pc}}$ evoked by $\mathrm{T} 1$ is inverted when $\mathrm{T} 2$ was expected on the side opposite to T1. Waveforms depict the difference right minus left hemisphere, $\mathrm{PO} 8-\mathrm{PO} 7$, when T2 was expected on the left side, and left minus right hemisphere, PO7-PO8, when T2 was expected on the right side. Bold lines denotes left side, thin lines denote right side, both of real T1 and of expected T2, thus the waveforms change line widths in the bottom panel where T2 was expected on the opposite side at a point in time here arbitrarily selected to be 300 msec after offset of the T1-evoked $\mathrm{N} 2$ pc. 
Figure 6. T2-evoked contralateral-ipsilateral differences. Grand means of the |left-right| differences, contralateral minus ipsilateral to the side of T1 from Experiment 1, separately for each SOA. Upper panels: PO8-PO7, from trials with T1 on the left. Bottom panels: PO7-PO8, from trials with T1 on the right. Time-point zero is $\mathrm{T} 1$ onset. The vertical arrows pointing to the $x$-axis denote the three alternative time points of T2 onset. Bold lines denote trials where $\mathrm{T} 2$ was on the left side (same side as T1 in the upper panels, opposite side in the lower panels), thin lines denote trials where T2 was on the right side (opposite to $\mathrm{T} 1$ in the upper panels, same side as T1 in the lower panels). (A) Data referred to pre-S1 baseline. (B) Lag 5 data subtracted from 0 to $600 \mathrm{msec}$, leaving only T2-related activity with Lags 1 and 2 . For the remaining data of Lag 5 , mean amplitude 600-650 msec was chosen as baseline to eliminate the remaining slow-wave activity induced by $\mathrm{T} 1$. The 100 -msec intervals used for measurement of $\mathrm{N} 2 \mathrm{pc}$ amplitude are denoted by horizontal lines. The dashed vertical lines in the Lag 5 panel denote $\mathrm{N} 2$ pc latency for left-side T2, which was earlier than for right-side $\mathrm{T} 2$.

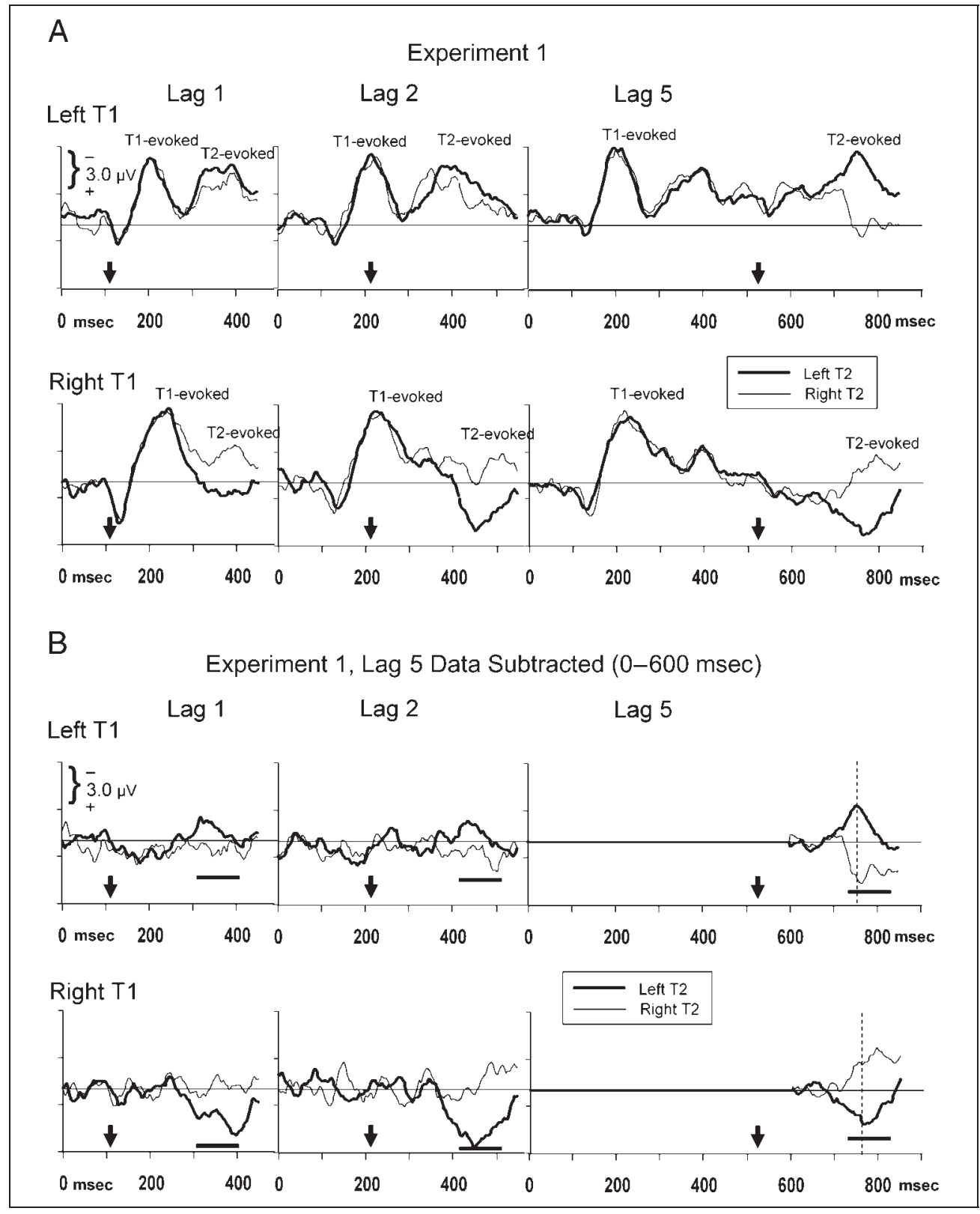

\section{Comparison of Unaffected vs. All Trials}

Performance in trials with gaze shifts and saccades could not be separately analyzed because there were too few trials, with four participants even having entirely missing data in some cells of the ANOVA. Therefore, in order to test within subjects for performance differences between the analyzed trials without gaze shifts to the other trials, comparison was made between the selected trials without gaze shifts and the total pool of unselected trials, using the above ANOVA design with the additional factor method (identification rates from trials without gaze shifts and without saccades vs. identification rates from all trials). No effects of method became significant, in particular, method did not interact with the left-right difference: All $F$ values of effects of method were $\leq 2.0, p \geq .18$, including interactions of Method $\times$ T2 side.

\section{Correlations}

Across participants, the rate of trials with gaze shifts and saccades, ranging between $8 \%$ and $40 \%$, tended to correlate with overall performance, such that participants who often moved their eyes performed worse in identifying T2|T1 $[r(11)=-.49, p=.09$, from trials without saccades; $r(11)=-.51, p=.07$, from unselected trials]. Of importance, rate of trials with gaze shifts and saccades did not correlate with the identification advantage of different-side left versus right targets $[r(11)=.27$, ns, from trials without saccades; 


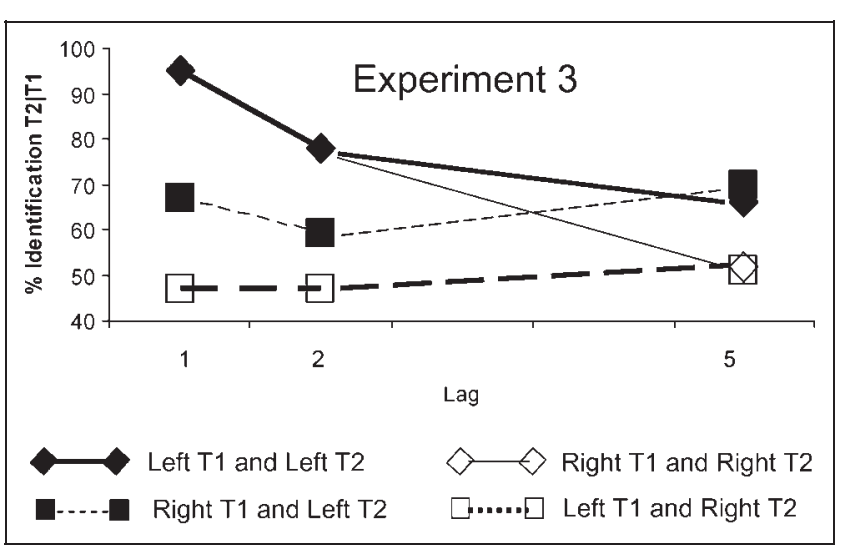

Figure 7. Identification rates for $\mathrm{T} 2$ in Experiment 3 (eye-movement control experiment). Displayed are percentages of correct T1 and $\mathrm{T} 2$ trials relative to all trials in which T1 was identified. Meaning of line styles and symbols is the same as in Figure 2. Note that by being almost identical to left $\mathrm{T} 1$ and $\mathrm{T} 2$ data, right $\mathrm{T} 1$ and $\mathrm{T} 2$ results of same-side trials (empty diamonds connected by thin solid lines) are hidden behind the corresponding left T1 and T2 data (filled diamonds connected by bold solid lines).

$r(11)=.23, n s$, from unselected trials]. Correlations between rate of trials with gaze shifts and saccades to identification rates of $\mathrm{T} 1$ (rather than T2) were lower and far from significance.

\section{Comparison to Experiment 1}

Direct comparison of identification rates between Experiment 1 and the unaffected trials of Experiment 3 yields an estimate of what portion of results of Experiment 1 were due to uncontrolled gaze shifts which now were sorted out from analysis. Probably this estimate is an overestimate, though, because participants of Experiment 3 had the additional mental and physical load of dealing with the eye-tracker which was uncomfortably firmly attached to their head, thereby possibly further decreasing their performance. ANOVA effects of the between-subjects factor experiment will be reported only. Identification rates were overall worse in the eye-control experiment, both for T1 [67\% vs. 78\%; Experiment: $F(1,21)=3.4, p=.08]$ and for $\mathrm{T} 2[65 \%$ vs. 78\%; Experiment: $F(1,21)=4.7, p=.04]$. This difference between experiments was not modified by other factors for identification of T1 (all interactions $F<2.6, p>.11$ ) but was so for T2: For right T2, performance was worse in Experiment 3 for Lag 5 only [Experiment $\times$ Lag: $F(2,42)=$ $7.0, p=.003$; Experiment $\times$ Lag $\times$ T2 side: $F(2,42)=$ $3.9, p=.04$; separate analysis for right T2: Experiment: $F(1,21)=3.2, p=.09$; Experiment $\times$ Lag: $F(2,42)=10.1$, $p=.001]$. For left $\mathrm{T} 2$, performance was generally worse in Experiment 3 [separate analysis for left T2: Experiment: $F(1,21)=5.2, p=.03$; Experiment $\times$ Lag: $F(2$, $42)=1.8, n s]$. This decrement of performance for left targets tended to be more marked when T1 was right
[Experiment $\times \mathrm{T} 1$ side $\times \mathrm{T} 2$ side: $F(1,21)=3.8, p=$ .06; separate effect of Experiment $\times$ T1 side for right-side T2: $F(1,21)=0.0, n s$; for left-side T2: $F(1,21)=3.2$, $p=.09$; separate effect of experiment for left-side T2 after left T1: $F(1,21)=3.8, p=.06$; after right T1: $F(1,21)=$ $5.5, p=.03]$. To summarize, the present strict eyemovement control induced two differences from Experiment 1 . The previous good performance with right T1 and left $\mathrm{T} 2$ at short lags deteriorated, making the difference between this performance and the still poor performance with left $\mathrm{T} 1$ and right $\mathrm{T} 2$ less drastic, although still clearly significant. Second, performance generally decreased at the longest lag.

\section{Electrophysiology}

Analysis of the ERPs recorded in this eye-movement control experiment was complicated by the fact that some participants had few trials only in some conditions. However, trials with left and with right T1 could be compared to each other, pooled across lags and side change. (Median number of trials in average: 118; range 26-277.) These data replicated the $\mathrm{N} 2{ }_{\mathrm{pc}}$ results from Experiment 1 very well (cf. Figure 3 and Figure 8). $\mathrm{N} 2 \mathrm{pc}$ was largest at $|\mathrm{PO} 7-\mathrm{PO} 8|$ and $|\mathrm{P} 7-\mathrm{P} 8|$ [Sites: $F(7,84)=18.51, p<.001]$. Like in Experiment 1 , peak amplitudes did not differ between T1 sides $(F<1.0)$, whereas peak latencies did, with $\mathrm{N} 2_{\mathrm{pc}}$ reaching its peak earlier with left $\mathrm{T} 1$ than with right $\mathrm{T} 1[F(1,12)=$ $14.4, p=.003]$. This effect of T1 side differed between pairs of sites [T1 side $\times$ Site: $F(7,84)=2.9, p=.04$ ] being significant at $|\mathrm{FC} 3-\mathrm{FC} 4|,|\mathrm{C} 1-\mathrm{C} 2|,|\mathrm{C} 3-\mathrm{C} 4|$, not at other sites [nor at hEOG; $F(1,12)=0.2, n s]$. Common analysis of these data with the $\mathrm{N} 2_{\mathrm{pc}}$ data from the Experiment 1, with experiment as additional factor, yielded no difference between experiments.

\section{DISCUSSION}

\section{Electrophysiological Correlates of the Right-hemisphere Advantage}

T2 was much better identified in sequences of right T1 and left T2 (R1-L2) than of left T1 and right T2 (L1-R2). In Experiment 1, this difference between sites amounted to $29 \%$ at the two shorter lags (77\% vs. $48 \%$ ) and was still appreciable at Lag 5 (13\%). These results provide a good replication of the findings made by Scalf et al. (2007, Experiment 6), Holländer, Corballis, and Hamm (2005), and Holländer, Hausmann, Hamm, and Corballis (2005).

By recording voltages between the hemispheres contralateral and ipsilateral to the targets separately for left-hemifield and right-hemifield targets, we were looking for mechanisms underlying this advantage of R1-L2. Of particular interest were differences between hemispheres in speed of processing, in sensitivity of processing, and in building up expectancies. 
Figure 8. T1-evoked contralateral-ipsilateral differences in Experiment 3 (eye-movement control experiment). Displayed are grand means of the |left-right| differences, contralateral minus ipsilateral to the side of T1, as was done in Figure 3 for the main experiment. See legend of Figure 3 for details.

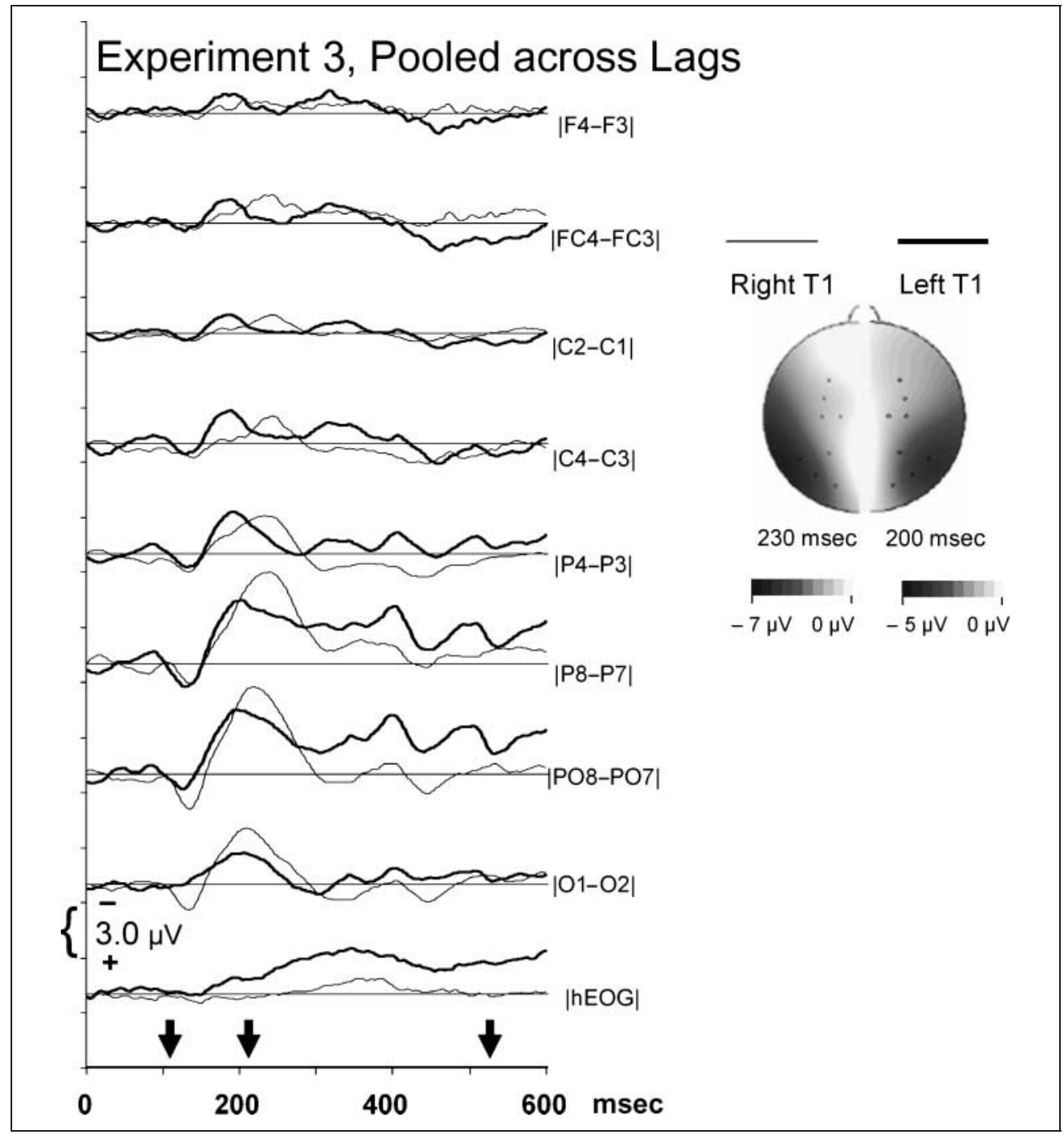

Phasic $N 2_{p c}$ Evoked by Left and Right $T 1$ and $T 2$

$\mathrm{N} 2_{\mathrm{pc}}$ reached its peak earlier after left than after right targets. This was true both for T1 and for T2 (measurable for T2 at Lag 5 only). Thus, the right hemisphere responded faster to its contralateral stimuli than the left hemisphere. In contrast to these latency differences, amplitudes evoked by T1 did not differ between left and right stimuli. However, with $\mathrm{T} 2, \mathrm{~N} 2_{\mathrm{pc}}$ was largest with the critical sequence R1-L2.

$\mathrm{N} 2_{\mathrm{pc}}$ has been interpreted to reflect selective processing of target features (see Introduction for references). Therefore, the latency results reveal that the right hemisphere was able to select or to process the target features faster than the left hemisphere in a fairly general manner, both in distinguishing the red color of T1 and in identifying the digit versus letter type of T2. This conclusion dovetails with magnetoencephalographic (MEG) measures from an RSVP task where two targets were presented centrally in close succession (Kessler et al., 2005). It was only at the right hemisphere that the MEG correlate of the P3 component had distinct peaks for both targets. Kessler et al. (2005) concluded accordingly that the right hemisphere is better able to single out events in time.

The amplitude results indicate that, although faster, the right hemisphere was not generally more activated by targets in its hemifield. Only with $\mathrm{T} 2$ did $\mathrm{N} 2{ }_{\mathrm{pc}}$ amplitude stand out with the critical combination R1-L2. That this amplitude was generally larger than in same-side sequences, L1-L2 and R1-R2, cannot be interpreted as characteristic to the present task because such reduction of $\mathrm{N} 2_{\mathrm{pc}}$ with same-side sequences of relevant stimuli has also been found in fast sequences of prime-target shapes, when the relevant shapes followed each other on the same side (Verleger \& Jaśkowski, 2007), therefore this reduction might be due to some process of habituation, perhaps determined purely by physiological refractoriness. However, the difference between R1-L2 and L1-R2 is not affected by this consideration. From this difference, it may be concluded that the right hemisphere indeed gets particularly activated by left-side 
targets, and further, because there is no such difference with $\mathrm{T} 1$, that this occurs particularly when attention has to be redirected. Alternatively, the finding may be highlighted that the R1-L2 > L1-R2 effect was significant at Lags 1 and 2 only, such that with Lag 5, N2 ${ }_{\mathrm{pc}}$ amplitude with right $\mathrm{T} 2 \mathrm{had}$ attained same size as with left $\mathrm{T} 2$. This might mean that the left hemisphere needs more time than the right hemisphere to single out a new target, which would point to differences between hemispheres in their capacities of temporal resolution, fitting the above conclusion derived from the $\mathrm{N} 2_{\mathrm{pc}}$ latency effects.

\section{Slow Negativity following the T1-evoked $N 2_{p c}$}

Two results were obtained for the slow negativity. First, the T1-evoked surplus of negativity at the contralateral hemisphere lasted longer after left than after right T1. Second, in Experiment 2, the possibility to expect $\mathrm{T} 2$ on the right side led to increased left-hemisphere negativity only if, already, $\mathrm{T} 1 \mathrm{had}$ been on the right but not if $\mathrm{T} 1$ had been on the left, whereas the right hemisphere always developed increased negativity when a left T2 could be expected, no matter on which side T1 was presented. Both results may be interpreted straightforwardly as indicating larger capacity of the right hemisphere for remaining activated and building up activation. Additionally, when adopting the view that the slow negativity reflects processing in working memory (Vogel et al., 2005; Vogel \& Machizawa, 2004), the aftereffects of T1 reflect more intensive processing in working memory after left-side than after right-side T1 and, more interestingly, the differences in expecting T2 on its cued side may indicate that the right hemisphere is better able to keep templates of the T2 exemplars active in visual working memory, making it easier to identify $\mathrm{T} 2$ by fitting these templates.

\section{Summary of Electrophysiological Results}

To summarize, these electrophysiological features indicated that the right hemisphere was faster in processing its contralateral stimuli, probably also was better able to single out events in time, and could maintain activation after targets and while expecting targets, possibly indicating the ability of the right hemisphere to activate target templates in working memory.

\section{Relation to Previous RSVP Research}

The time courses of $\mathrm{T} 2$ identification obtained for sameside and different-side T1-T2 sequences differed both from each other and from the time courses usually obtained in RSVP tasks where one stream of stimuli is presented. That usual time course is nonmonotonic, with good T2 identification at Lags 1 and 5 and worsened performance in-between (Nieuwenhuis, Gilzenrat,
Holmes, \& Cohen, 2005). In contrast, in our experiments, both the same-side and the different-side time courses were monotonic: With T1 and T2 on the same side, T2 identification was very good at Lag 1 and became progressively worse with longer lags. With T1 and $\mathrm{T} 2$ on different sides, T2 identification was poor at Lags 1 and 2 and became better with longer lags. In fact, similar results were reported by preceding studies that presented T1 and T2 within RSVPs at different locations (Holländer, Corballis, \& Hamm, 2005; Peterson \& Juola, 2000; Shih, 2000; Breitmeyer et al., 1999). Although the results differ from the one-stream RSVP results, it appears possible to account for these findings by means of the concepts developed to account for the one-stream results, as mentioned in the Introduction: T1 temporarily increases the level of attention, which makes the following distracters processed attentively and impedes shifting to the new criteria needed for detecting T2 (Olivers, 2007; Nieuwenstein \& Potter, 2006; Di Lollo et al., 2005). In the present situation, the assumption has to be added that the increase of the level of attention in case of a lateral T1 means that T1 immediately draws the spatial focus of attention to its stream, by containing the searched feature, like in experiments with peripheral cues (Folk, Remington, \& Johnston, 1992). With attention thereby increased on the T1 side, T2 immediately occurring on this side has good chances of getting identified, whereas T2 occurring on the other side occurs outside the focus of spatial attention. When no T2 is immediately detected, spatial attention would be reinstalled to cover both sides equally, such that at Lag 5, T2 had approximately equal probability of getting identified in same-side and different-side sequences.

By this account, the large asymmetry in $\mathrm{T} 2$ detection between hemifields with different side sequences indicates that some process of these reallocations of spatial attention is biased toward the left hemifield. In terms of Posner (1986), this reallocation consists of the processes of attention being disengaged from T1, moving to T2, and being engaged by T2. In Scalf et al.'s (2007) data, these processes may be distinguished. In that study, T1 and T2 could occur in one of four locations, upper left, lower left, upper right, lower right, making it possible to compare different-location T1-T2 sequences between the equidistant spatial shifts $\mathrm{L}-\mathrm{L}, \mathrm{L}-\mathrm{R}, \mathrm{R}-\mathrm{R}, \mathrm{R}-\mathrm{L}$. The decisive factor proved to be $\mathrm{T} 2$ side: Left $\mathrm{T} 2$, both in $\mathrm{L}-\mathrm{L}$ and $\mathrm{R}-\mathrm{L}$ sequences, was better identified than right $\mathrm{T} 2$ ( $\mathrm{R}-\mathrm{R}$ and $\mathrm{L}-\mathrm{R}$ sequences). The result is inconsistent with an account that the $\mathrm{R}-\mathrm{L}$ advantage mainly reflects a preference for moving attention from right to left over moving from left to right, because then L-L should not be better than R-R. Likewise, it is inconsistent with an account that the $\mathrm{R}-\mathrm{L}$ advantage reflects a problem in disengaging attention from the left hemifield with $\mathrm{L}-\mathrm{R}$ sequences, because then $\mathrm{R}-\mathrm{R}$ should not be worse than L-L. Rather, the crucial factor seems to be which hemisphere is dealing with T2. From the above-discussed 
electrophysiological results, it may be said that this is so because the right hemisphere is better able to single out $\mathrm{T} 2$ because of its faster processing and possibly because of better capacity of visual working memory.

\section{Moderating Factors}

When eye movements were controlled by the headmounted infrared tracker, the right-hemisphere advantage was still obtained, although modified in two ways: First, it became somewhat weaker at the short lags. Second, at the longest lag, performance was generally worse than without eye-movement control, in both hemifields. Several interpretations are possible for these effects. First, one might argue that, indeed, some part of the large effect in our Experiment 1 as well as in the previous studies (Scalf et al., 2007; Holländer, Corballis, \& Hamm, 2005; Holländer, Hausmann, Hamm, \& Corballis, 2005) was due to failures of fixation, with participants having permanently shifted their gaze to the left. Alternatively, these effects may reflect the influence of strategic settings. Possibly, by knowing that their eye movements would be strictly controlled, permanently reminded by the pressure of the tight strap around their head, participants felt discouraged from shifting their attention not only overtly, by moving their eyes, but also covertly, due to the strong connection between both processes (e.g., Deubel \& Schneider, 1996), thus not making optimal use of their capacities. The main point of the eye-movement control experiment, however, is that the major part of the left-hemifield advantage obtained in previous experiments still occurred when eye movements were strictly controlled.

Results of Experiment 2 showed that the effect could be further modified although not abolished by strategic adaptations: When the position of T1 provided the cue to expect $\mathrm{T} 2$ on the other side, the right-hemisphere advantage was absent at Lag 5, but at the short lags there was still a difference of $20 \%$ in T2 identification between hemifields (Figure 2, bottom). The mechanism underlying this slow compensation, effective at Lag 5, probably was an endogenously cued shift of spatial attention, known to be a relatively slow process since the studies by Reeves and Sperling (1986) and Sperling and Reeves (1980) where, in tasks similar to the present ones, a letter had to be identified in the left stream and then numbers had to be reported from the right stream. An "attention reaction time" of about 400 msec was obtained in those studies.

On the other hand, our finding that the right-hemisphere advantage was only weakened but did not disappear when subjects knew that T1 and T2 would never appear in the same stream is in contrast to Scalf et al.'s (2007) Experiments 2, 3b, 4, and 5, where the effect totally disappeared under these conditions. One obvious difference from our study is the number of stimulus streams. Possibly, the presentation of streams at all four quad- rants of the visual field induced Scalf et al.'s participants to abandon a strictly focused mode of attention. It has been shown in one-stream RSVP that such a relaxed attitude might actually be beneficial for T2 identification (Olivers \& Nieuwenhuis, 2006). Speculatively, the same might apply here. Another divergent result was reported by Kawahara and Yamada (2006): Simultaneously presented different letters had to be identified as double T1 and T2 in left and right RSVP streams. The left-side T2 was not identified better than the right-side T2. A number of factors might have made the left-hemifield advantage disappear, including the simultaneous presentation of different information in both hemifields, and the task required for $\mathrm{T} 1$ where participants just had to indicate whether T1 was the same in the left and right stream or not. Indeed, in a follow-up study where the two T1 stimuli had to be identified in their own right (Yamada \& Kawahara, 2007), separate analysis for left and right T2 in Experiments 1 and 2 yielded lefthemifield advantages in T2 identification (J. Kawahara, personal communication, January 14, 2008). Further studies are needed to clarify these issues.

An obvious question is how specific is the difference between hemifields to the target stimuli used, which were letters or digits in all experiments reported so far. It must be noted that if anything, letters, being the building blocks of verbal material, should be better processed by the left than by the right hemisphere (e.g., Maurer, Brem, Bucher, \& Brandeis, 2005), just opposite to the present results. Furthermore, the sequence of targets that corresponds to left-to-right reading (left T1, right T2) was precisely the one where $\mathrm{T} 2$ was identified worst. Nevertheless, stimulus material should be varied in future studies in order to bolster these claims.

\section{Evidence on the Right-hemisphere Advantage in RSVP from Lesion and Activation Studies}

In accordance with the present electrophysiological results, a special role of the right hemisphere in RSVP tasks has been suggested by studies on neglect patients with right hemisphere lesions who, compared to righthemisphere stroke patients without neglect and healthy controls, were severely impaired in their ability to detect T2 even when stimuli were centrally presented (Husain, Shapiro, Martin, \& Kennard, 1997) and, as a matter of course, when T2 was presented in the neglected left hemispace (Hillstrom, Husain, Shapiro, \& Rorden, 2004). Any special role of the right hemisphere was, however, questioned by other patient studies who found deficient T2 detection also in patients with lesions of the left hemisphere or of the cerebellum (Schweizer, Alexander, Cusimano, \& Stuss, 2007; Rizzo, Akutsu, \& Dawson, 2001). Thus, probably more parts of the brain than just the right hemisphere are needed to cope with the difficult task of detecting targets in RSVP, with some lesion to any part of the system being able to impede 
performance. But this plausible argument does not disprove an advantage of the right hemisphere in healthy brains. Possibly more critical is the report about the splitbrain patient $\mathrm{J}$. W. whose intact right hemisphere did not have any advantage but rather a severe disadvantage in identifying T2 letters in its contralateral visual field (Giesbrecht \& Kingstone, 2004). In defense of the righthemisphere advantage, it may be argued that J. W. had general severe problems in processing letters presented to the left hemifield, even to the extent that identical letters did not prime responses by their form (Gazzaniga, 1995). In line with this general deficit, J. W. also had considerable asymmetry in T1 identification (76\% left, $94 \%$ right), such that it remains unclear, indeed, how much his right-hemisphere deficit for T2 identification was due to an interaction of RSVP with this hemisphere's general deficit in processing left-hemifield letters.

A special role of the right hemisphere could not be confirmed by those previous fMRI studies that used RSVP, always in central presentation, and distinguished between detected and missed T2 (Kranczioch, Debener, Schwarzbach, Goebel, \& Engel, 2005; Marois, Yi, \& Chun, 2004; for other studies associated with RSVP, see Marcantoni, Lelage, Beaudoin, Gourgouin, \& Richer, 2003; Marois, Chun, \& Gore, 2000). Both Kranczioch et al. (2005) and Marois et al. (2004) reported that T2 detection is associated with increased activation in the lateral frontal and anterior cingulate cortex and, important to the present point, that there is no increase of right-hemisphere compared to left-hemisphere activation in any of the studied relevant areas. To the contrary, the asymmetry found by Kranczioch et al., in the inferior parietal lobe, was in favor of the left hemisphere. Possibly, the reliable small advantages in perceptual speed indicated by our electrophysiological measures occur on a time scale difficult to measure with the relatively slow changes of blood oxygenation reflected by fMRI.

\section{Significance}

As noted in the Introduction, the present task seems exceptional for its drastic differences in performance between hemifields, in favor of the left hemifield and of the right hemisphere. Differences usually obtained are much more subtle (e.g., Hilgetag, Théoret, \& PascualLeone, 2001) but, on the other hand, when present are only mentioned in passing if at all (e.g., Wendt, Kluwe, \& Vietze, 2008). It remains uncertain how relevant this right-hemisphere advantage is to everyday perception. Possibly, this advantage becomes evident in extreme situations only, such as the situation represented by the present task. On the other hand, the unpredictable moment-to-moment changes of perceptual input that we encounter when walking through crowded streets or when driving through diversified environments might well constitute just such situations.

\section{Acknowledgments}

Piotr Jaśkowski and Stefanie Kraft were supported by a grant from the Deutsche Forschungsgemeinschaft to Rolf Verleger (Ve 110/13-1). We thank the reviewers for their many constructive comments.

Reprint requests should be sent to Rolf Verleger, Klinik für Neurologie, Universität Lübeck, 23538 Lübeck, Germany, or via e-mail: rolf.verleger@neuro.uni-Luebeck.de.

\section{REFERENCES}

Breitmeyer, B. G., Ehrenstein, A., Pritchard, K., Hiscock, M., \& Crisan, J. (1999). The roles of location specificity and masking mechanisms in the attentional blink. Perception $E$ Psychophysics, 61, 798-809.

Chambers, C. D., Payne, J. M., Stokes, M. G., \& Mattingley, J. B. (2004). Fast and slow parietal pathways mediate spatial attention. Nature Neuroscience, 7, 217-218.

Corballis, M. C. (1997). Mental rotation and the right hemisphere. Brain and Language, 57, 100-121.

Corbetta, M., Miezin, F. M., Shulman, G. L., \& Petersen, S. E. (1993). A PET study of visuospatial attention. Journal of Neuroscience, 13, 1202-1226.

Danckert, J., \& Ferber, S. (2006). Revisiting unilateral neglect. Neuropsychologia, 44, 987-1006.

Dell'Acqua, R., Pascali, A., Jolicœur, P., \& Sessa, P. (2003). Fourdot masking produces the attentional blink. Vision Research, 43, 1907-1913.

Dell'Acqua, R., Sessa, P., Jolicœur, P., \& Robitaille, N. (2006). Spatial attention freezes during the attentional blink. Psychophysiology, 43, 394-400.

Deubel, H., \& Schneider, W. X. (1996). Saccade target selection and object recognition: Evidence for a common attentional mechanism. Vision Research, 36, 1827-1837.

Di Lollo, V., Kawahara, J., Ghorashi, S. M. S., \& Enns, J. T. (2005). The attentional blink: Resource depletion or temporary loss of control? Psychological Research, 69, 191-200.

Driver, J., \& Vuilleumier, P. (2001). Perceptual awareness and its loss in unilateral neglect and extinction. Cognition, 79, 39-88.

Eimer, M. (1996). The N2pc component as an indicator of attentional selectivity. Electroencephalography and Clinical Neurophysiology, 99, 225-234.

Folk, C. L., Remington, R. W., \& Johnston, J. C. (1992). Involuntary covert orienting is contingent on attentional control settings. Journal of Experimental Psychology: Human Perception and Performance, 18, 1030-1044.

Gazzaniga, M. S. (1995). Principles of human brain organization derived from split-brain studies. Neuron, 14, 217-228.

Giesbrecht, B., \& Kingstone, A. (2004). Right hemisphere involvement in the attentional blink: Evidence from a split-brain patient. Brain and Cognition, 55, 303-306.

Hilgetag, C. C., Théoret, H., \& Pascual-Leone, A. (2001). Enhanced visual spatial attention ipsilateral to rTMS-induced "virtual lesions" of human parietal cortex. Nature Neuroscience, 4, 953-957.

Hillstrom, A. P., Husain, M., Shapiro, K. L., \& Rorden, C. (2004). Spatiotemporal dynamics of attention in visual neglect: A case study. Cortex, 40, 433-440

Holländer, A., Corballis, M. C., \& Hamm, J. P. (2005). Visual-field asymmetry in dual-stream RSVP. Neuropsychologia, 43, 35-40.

Holländer, A., Hausmann, M., Hamm, J. P., \& Corballis, M. C. (2005). Sex hormonal modulation of hemispheric asymmetries in the attentional blink. Journal of the International Neuropsychological Society, 11, 263-272. 
Hopf, J.-M., Luck, S. J., Boelmans, M. A., Schoenfeld, M. A., Boehler, C. N., Rieger, J., et al. (2006). The neural site of attention matches the spatial scale of perception. Journal of Neuroscience, 26, 3532-3540.

Husain, M., Shapiro, K., Martin, J., \& Kennard, C. (1997). Abnormal temporal dynamics of visual attention in spatial neglect patients. Nature, 385, 154-156.

Jolicour, P., Sessa, P., Dell'Acqua, R., \& Robitaille, N. (2006). On the control of visual spatial attention: Evidence from human electrophysiology. Psychological Research, 70, 414-424.

Kawahara, J.-I., \& Yamada, Y. (2006). Two noncontiguous locations can be attended concurrently: Evidence from the attentional blink. Psychonomic Bulletin \& Review, 13, 594-599.

Kessler, K., Schmitz, F., Gross, J., Hommel, B., Shapiro, K., \& Schnitzler, A. (2005). Cortical mechanisms of attention in time: Neural correlates of the Lag-1-sparing phenomenon. European Journal of Neuroscience, 21, 2563-2574.

Kinsbourne, M. (1987). Mechanisms of unilateral neglect. In M. Jeannerod (Ed.), Neurophysiological and neuropsychological aspects of spatial neglect (pp. 69-86) Amsterdam: Elsevier.

Kranczioch, C., Debener, S., Schwarzbach, J., Goebel, R., \& Engel, A. K. (2005). Neural correlates of conscious perception in the attentional blink. Neuroimage, 24, 704-714.

Luck, S. J., \& Hillyard, S. A. (1994). Electrophysiological correlates of feature analysis during visual search. Psychophysiology, 31, 291-308.

Marcantoni, W. S., Lelage, M., Beaudoin, G., Gourgouin, P., \& Richer, F. (2003). Neural correlates of dual task interference in rapid visual streams: An fMRI study. Brain and Cognition, 53, 318-321.

Marois, R., Chun, M. M., \& Gore, J. C. (2000). Neural correlates of the attentional blink. Neuron, 28, 299-308.

Marois, R., Yi, D.-J., \& Chun, M. M. (2004). The neural fate of consciously perceived and missed events in the attentional blink. Neuron, 41, 465-472.

Maurer, U., Brem, S., Bucher, K., \& Brandeis, D. (2005). Emerging neurophysiological specialization for letter strings. Journal of Cognitive Neuroscience, 17, 1532-1552.

Naccache, L., Blandin, E., \& Dehaene, S. (2002). Unconscious masked priming depends on temporal attention. Psychological Science, 13, 416-424.

Nieuwenhuis, S., Gilzenrat, M. S., Holmes, B. D., \& Cohen, J. D. (2005). The role of the locus coeruleus in mediating the attentional blink: A neurocomputational theory. Journal of Experimental Psychology: General, 134, 291-307.

Nieuwenstein, M. R., \& Potter, M. C. (2006). Temporal limits of selection and memory encoding: A comparison of whole versus partial report in rapid serial visual presentation. Psychological Science, 17, 471-475.

Nobre, A. C., Sebestyen, G. N., Gitelman, D. R., Mesulam, M. M., Frackowiak, R. S. J., \& Frith, C. D. (1997). Functional localization of the system for visuospatial attention using positron emission tomography. Brain, 120, 515-533.

Olivers, C. N. L. (2007). The time course of attention: It is better than we thought. Current Directions in Psychological Science, 16, 11-15.

Olivers, C. N. L., \& Nieuwenhuis, S. (2006). The beneficial effects of additional task load, positive affect, and instruction on the attentional blink. Journal of Experimental Psychology: Human Perception and Performance, 32, 364-379.

Peterson, M. S., \& Juola, J. F. (2000). Evidence for distinct attentional bottlenecks in attention switching and attentional blink tasks. Journal of General Psychology, 127, 6-26.

Posner, M. I. (1986). A framework for relating cognitive to neural Systems. In W. C. McCallum, R. Zappoli, \& F. Denoth
(Eds.), Cerebral psychophysiology: Studies in event-related potentials (EEG Suppl. 38) (pp. 155-166). Amsterdam: Elsevier.

Potter, M. C. (2006). Competition for attention in space and time: The first 200 ms. In H. Öğmen \& B. Breitmeyer (Eds.), The first half second: The microgenesis and temporal dynamics of unconscious and conscious visual processes (pp. 207-224). Cambridge: MIT Press.

Raymond, J. E., Shapiro, K. L., \& Arnell, K. M. (1992). Temporary suppression of visual processing in an RSVP task: An attentional blink? Journal of Experimental Psychology: Human Perception and Performance, 18, 849-860.

Reeves, A., \& Sperling, G. (1986). Attention gating in short-term visual memory. Psychological Review, 93, 180-226.

Rizzo, M., Akutsu, H., \& Dawson, J. (2001). Increased attentional blink after focal cerebral lesions. Neurology, 57, 795-800.

Rushworth, M. F. S., Ellison, A., \& Walsh, V. (2001). Complementary localization and lateralization of orienting and motor attention. Nature Neuroscience, 4, 656-661.

Scalf, P. E., Banich, M. T., Kramer, A. F., Narechania, K., \& Simon, C. D. (2007). Double take: Parallel processing by the cerebral hemispheres reduces the attentional blink. Journal of Experimental Psychology: Human Perception and Performance, 33, 298-329.

Schweizer, T. A., Alexander, M. P., Cusimano, M., \& Stuss, D. T. (2007). Fast and efficient visuotemporal attention requires the cerebellum. Neuropsychologia, 45, 3068-3074.

Shih, S.-I. (2000). Recall of two visual targets embedded in RSVP streams of distractors depends on their temporal and spatial relationship. Perception \& Psychophysics, 62, 1348-1355.

Sperling, G., \& Reeves, A. (1980). Measuring the reaction time of a shift of visual attention. In R. Nickerson, (Ed.), Attention and performance VIII (pp. 347-360). Hillsdale, NJ: Erlbaum.

Vachon, F., Tremblay, S., \& Jones, D. M. (2007). Task-set reconfiguration suspends perceptual processing: Evidence from semantic priming during the attentional blink. Journal of Experimental Psychology: Human Perception and Performance, 33, 330-347.

Verleger, R., \& Jaśkowski, P. (2007). Disentangling neural processing of masked and masking stimulus by means of event-related contralateral-ipsilateral differences of EEG potentials. Advances in Cognitive Psychology, 3, 193-210.

Vogel, E. K., \& Machizawa, M. G. (2004). Neural activity predicts individual differences in visual working memory capacity. Nature, 428, 748-751.

Vogel, E. K., McCollough, A. W., \& Machizawa, M. G. (2005). Neural measures reveal individual differences in controlling access to working memory. Nature, 438, 500-503.

Wauschkuhn, B., Verleger, R., Wascher, E., Klostermann, W., Burk, M., Heide, W., et al. (1998). Lateralised human cortical activity for shifting visuospatial attention and initiating saccades. Journal of Neurophysiology, 80, 2900-2910.

Wendt, M., Kluwe, R. H., \& Vietze, I. (2008). Location-specific versus hemisphere-specific adaptation of processing selectivity. Psychonomic Bulletin \& Review, 15, 135-140.

Woldorff, M. G., Hazlett, C. J., Fichtenholtz, H. M., Weissman, D. H., Dale, A. M., \& Song, A. W. (2004). Functional parcellation of attentional control regions of the brain. Journal of Cognitive Neuroscience, 16, 149-165.

Woodman, G. F., \& Luck, S. J. (1999). Electrophysiological measurement of rapid shifts of attention during visual search. Nature, 400, 867-869.

Yamada, Y., \& Kawahara, J.-I. (2007). Dividing attention between two different categories and locations in rapid serial visual presentations. Perception \& Psychophysics, 69, $1218-1239$. 